\title{
Effect of Phentolamine on Perfusate Flow Characteristics during Renal Preservation
}

\author{
THOMAS R. WEBER, M. D., DUANE T. FREIER, M. D., \\ CLAUDIO A. SALLES, M. D., STEPHEN R. RAMSBURGH, M. D., \\ AND S. MARTIN LINDENAUER, M.D. \\ Department of Surgery, University of Michigan Medical Center and Surgical Service, \\ Veterans Administration Hospital, 2215 Fuller Road, Ann Arbor, Michigan 48105
}

Submitted for publication June 19, 1975

Despite continuing improvements in the technique of hypothermic perfusion of cadaver kidneys, some renal transplants do not function after such preservation for any apparent reason. The presence of shock, sepsis, low perfusion states, or hypoxia in the cadaver donor has profound effects on the perfused cadaver kidney, due partly to catecholamine-induced intrarenal vasoconstriction [2]. In addition, there is evidence that the vasoconstriction persists after transplantation which may lead to acute renal failure [1].

Recently, Miller et al. have shown the salutary effects that an $\alpha$-adrenergic blocking agent, phentolamine, has on the flow characteristics of the perfused kidney, both experimentally and clinically [7]. These investigators suggest that the post-transplantation function of cadaver kidneys might be improved using intraarterial phentolamine during perfusion. Several investigators $[5,6]$ have shown experimentally that the intrarenal distribution of perfusate during isolatcd, hypothermic perfusion is adversely affected by hypoxia in the donor animal, probably due to intrarenal vasoconstriction induced by circulating catecholamines. The characteristic pattern is a decreased percentage of perfusate flow to the renal cortex of varying degree, depending upon the condition of the donor and the warm ischemic time prior to perfusion [6]. However, the effects of $\alpha$-adrenergic blockage with phentolamine on the intrarenal distribution of perfusate in the preserved kidney have not been extensively evaluated.
This study is an attempt to define the intrarenal distribution of perfusate in the hypothermic preserved kidney removed from hypoxic donor animals. In addition, the effects of phentolamine on the intrarenal distribution of perfusate were investigated.

\section{METHODS}

Adult mongrel dogs of either sex, weighing between 15 and $22 \mathrm{~kg}$, were used throughout the study. Anesthesia was induced and maintained with small intermittent doses of Surital. Each animal underwent endotracheal intubation, and ventilation was maintained with a Harvard respirator. Normal saline $(1000$ $\mathrm{ml}$ ) was administered intravenously during the operation, and at the initiation of the kidney dissection each animal received $12.5 \mathrm{~g}$ of mannitol and $3 \mathrm{mg} / \mathrm{kg}$ of heparin intravenously. Immediately after removal, each kidney was flushed intraarterially with $200-300 \mathrm{ml}$ of Ringer's lactate solution with 1000 units of heparin utilizing $100 \mathrm{~cm}$ of water gravity flow. The kidney was placed on a Waters Mox-100 pulsatile perfusion unit. ${ }^{1}$ The perfusate was cryoprecipitated, filtered dog plasma prepared in our laboratory. Additives to each liter of perfusate were: 8 mequiv of magnesium sulfate, 80 units of regular insulin, $500 \mathrm{mg}$ of methylprednisolone, 500,000 units of aqueous penicillin, and $12 \mathrm{mg}$ of phenosulfonphthalein. The perfusate was maintained at $6^{\circ} \mathrm{C}$ and was oxygenated through a self-contained membrane oxygenator. The perfusion pressure was initially set

\footnotetext{
${ }^{1}$ Waters Instruments, Inc., Rochester, Minn.
} 
at $60 \mathrm{~mm} \mathrm{Hg}$. The flow rate through the kidney was determined volumetrically immediately after the onset of perfusion, at hourly intervals for the first $6 \mathrm{hr}$, and at 12 and $24 \mathrm{hr}$. The intrarenal distribution of perfusate was determined utilizing the following xenon-133 washout technique: The disappearance of $x$ cnon-133 injected into the renal artery portal of the cassette was recorded by an external scintillation counter connected to a rate meter and a linear chart recorder. The resulting curve was plotted on semilogarithmic paper, and the record was partitioned into three components by the serial subtraction method [10], corresponding to: outer cortical flow (component I), inner cortical and outer medullary flow (component II), and inner medullary flow (component III). The half-time $\left(T_{1 / 2}\right)$ for each component was determined from the slope of each curve and substituted in to the formula:

renal blood flow (RBF)

$$
=(\ln 2 \times \lambda \times 100) / T_{1 / 2},
$$

where RFB is expressed in $\mathrm{cm}^{3} / 100 \mathrm{~g}$ of tissue/min and $\lambda$ is the kidney-plasma partition coefficient (1.21) [4]. Substitution of known values in the formula reduces it to a simplified form: $\mathrm{RFB}=83.85 / T_{1 / 2}$. The percentage of perfusate flow to each component was determined by extrapolation of each curve to time zero [10]. Xenon-133 flows were performed on each kidney at 1,5 and $24 \mathrm{hr}$ after the onset of perfusion.

Five groups of kidneys werc studied to determine the effects of hypoxia, warm ischemia, and phentolamine on the intrarenal distribution of perfusate as follows:

Group I. Five kidneys were removed from animal donors with normal blood pressure, pulse, and urine output.

Group II: Five kidneys werc removed from animals within 2-3 min following anoxic cardiac arrest. Anoxia was produced in this group and all subsequent groups by clamping the endotracheal tube, with cardiac arrest invariably occurring within 8-12 min.

Group III. Five kidneys were removed from anoxic animals and, in addition, warm ischemia was induced by allowing the kidneys to remain in the abdomen for $40-50 \mathrm{~min}$ before perfusion.

Group $I V$. Six kidneys were removed from donors as in Group II, but with phentolamine, $15 \mathrm{mg}$, infused over 3-5 min directly into the renal artery $15 \mathrm{~min}$ after the onset of perfusion.

Group $V$. Five kidneys were removed from donors as in Group III, but with phentolamine, $15 \mathrm{mg}$, infused over $3-5 \mathrm{~min}$ directly into the renal artery $15 \mathrm{~min}$ after the onset of perfusion. The experimental groups are summarized in Table 1.

\section{RESULTS}

The total kidney perfusate flows measured after $1 \mathrm{hr}$ of perfusion and after $24 \mathrm{hr}$ of perfusion are shown in Fig. 1. The control kidneys (Group I) had a mean flow of 124 $\mathrm{cm}^{3} / \mathrm{min}$. which did not change significantly after $24 \mathrm{hr}$ of perfusion. Kidneys subjected to donor anoxia (Group II) and anoxia plus 45 min of warm ischemia (Group III) had mean 1-hr flow rates of $48 \mathrm{~cm}^{3} / \mathrm{min}$ and $51 \mathrm{~cm}^{3} /$ min, respectively. These flows improved slightly after $24 \mathrm{hr}$ of perfusion but remained significantly lower than control kidneys $(P<$ $0.05)$. Intraarterial phentolamine signifi-

TABLE 1

Summary of Experimental Groups

\begin{tabular}{lcll} 
Group & $\begin{array}{c}\text { Number of } \\
\text { Kidneys }\end{array}$ & \multicolumn{1}{c}{ Experiment } & Treatment \\
\hline I & 5 & Normal (control) & None \\
II & 5 & Anoxia & None \\
III & 5 & Anoxia + warm ischemia & None \\
IV & 6 & Anoxia & I.A. phentolamine \\
V & 5 & Anoxia + warm ischemia & I.A. phentolamine \\
\hline
\end{tabular}




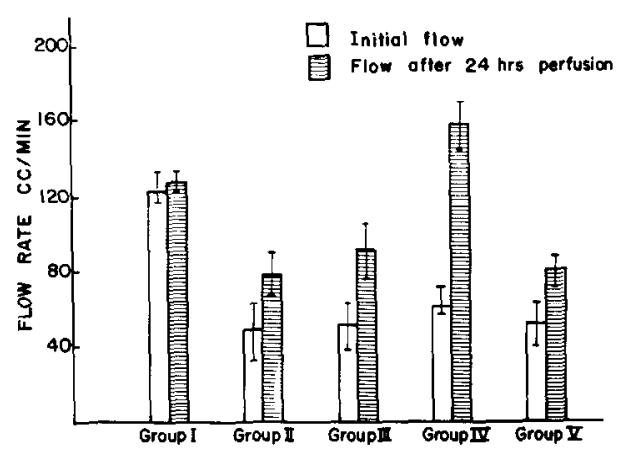

FIG. 1. Total kidney perfusate flow after 1 and $24 \mathrm{hr}$ of hypothermic perfusion (mean $\pm \mathrm{SE}$ ). Note lower flow rates in Groups II and III compared to control ( $P<$ $0.05)$, increase in flow in Group III $(P<0.01)$, and no significant change in Group V $(P>0.05)$.

cantly improved the flow rate of the anoxic kidneys (Group IV) $(P<0.05$ compared to control) but did not increase the flow rate of the kidneys subjected to donor anoxia plus 45 min of warm ischemia (Group V) $(P>0.05$ compared to control).

The changes in the xenon-133 washout pattern with perfusion and intraarterial phentolamine for the various groups during $24 \mathrm{hr}$ of perfusion are shown in Fig. 2. The outer cortex of the control kidneys received an average of $78 \%$ of the total perfusate flow throughout the 24-hr perfusion. Donor anoxia (Group II) and anoxia plus warm ischemia (Group III) both were associated with a reduced outer cortical flow to a mean of 45

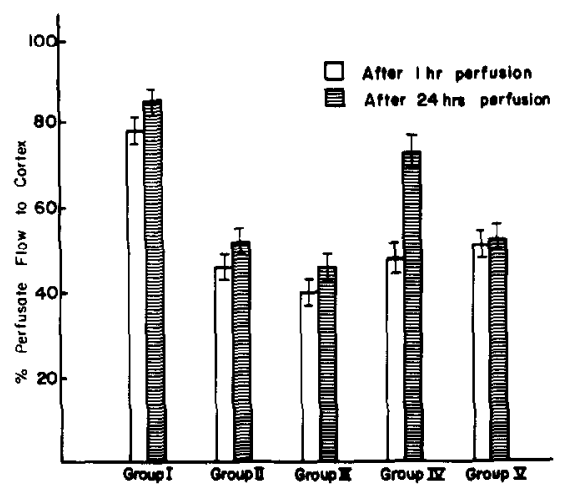

FIG. 2. Outer cortex flow measured by xenon-133 clearance (mean $\pm \mathrm{SE}$ ) after $I$ and 24 hr of hypothermic perfusion. Note decrease in cortical flow in Groups II, III, and $\mathrm{V}$ and increase in cortical flow approaching control levels at 24 hr in Group IV.

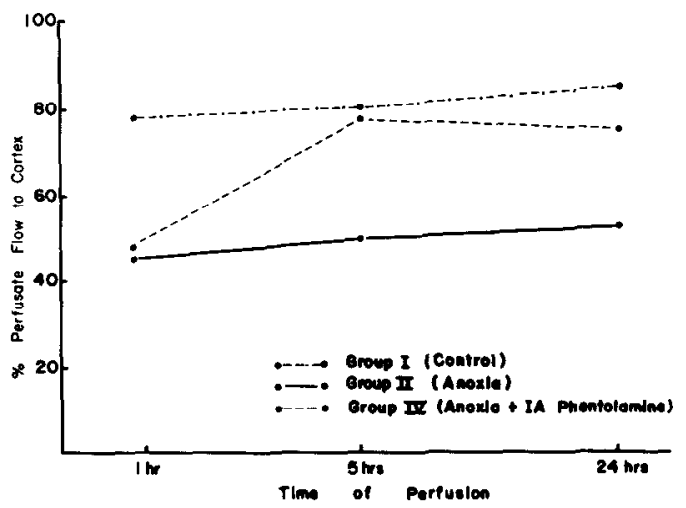

FIG. 3. Effect of intraarterial phentolamine on outer cortical perfusate flow in kidneys subjected to anoxia.

and $42 \%$, respectively, of total perfusate flow ( $P<0.05$ compared to control). This reduction in perfusion to the outer cortex persisted throughout the $24 \mathrm{hr}$.

Intraarterial phentolamine reversed the effects of anoxia on outer cortical flow (Group IV). These kidneys had a xenon-133 washout pattern after $5 \mathrm{hr}$ of perfusion that approached control levels (average cortical flow of $72 \%$ ), and the pattern persisted throughout the $24 \mathrm{hr}$ (Figs. 2 and 3). However, phentolamine did not improve the outer cortical flow in kidneys subjected to donor anoxia plus warm ischemia (Group V). In this group the outer cortex continued to receive only $52 \%$ of the perfusate flow. (Figs. 2 and 4). Figure 5 demonstrates that the perfusion flow to the outer cortex is decreased while

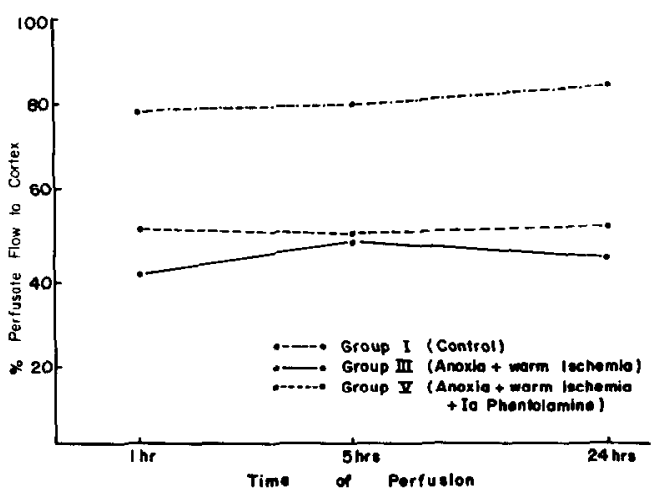

FIG. 4. Effect of intraarterial phentolamine on outer cortical perfusate flow in kidneys subjected to anoxia and warm ischemia. 


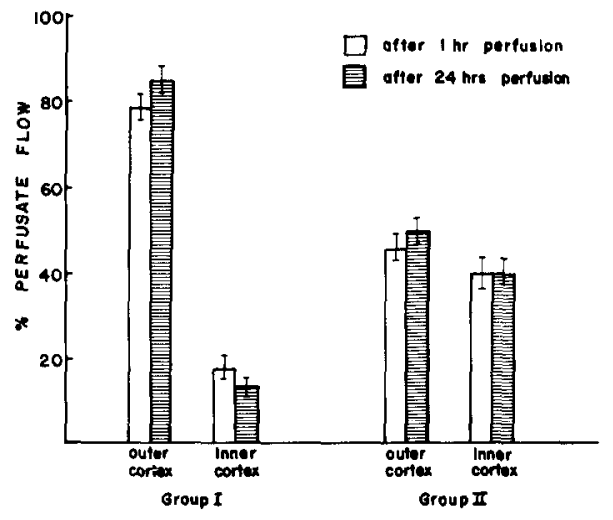

FIG. 5. Distribution of perfusate flow to inner and outer cortex in normal kidneys (Group I) and kidneys subjected to anoxia (Group II) during $24 \mathrm{hr}$ of hypothermic perfusion (mean $\pm \mathrm{SE}$ ).

flow to the inner cortex is increased in response to donor anoxia. This pattern persists throughout the period of perfusion. In normal kidneys, the outer and inner cortical flows are 80 and $15 \%$ of total flow, respectively.

\section{DISCUSSION}

Postperfusion renal shutdown has received a great deal of attention since renal preservation was first attempted, but only recently has the importance of the circulatory status of the cadaver donor before nephrectomy been recognized. Intrarenal vasoconstriction is a well-recognized consequence of low perfusion status [3] and donor hypoxia [7] or a combination of these effects, and this appears to persist after transplantation [1]. There is also evidence that the agonal effects of circulating catecholamines may be more important in post-transplant renal shutdown than warm ischemia alone, both in terms of intrarenal perfusate distribution [6] and posttransplant function [2]. The importance of cortical flow to renal function both in vivo [8] and in vitro [9] has also been emphasized by other investigators.

Renal perfusion can be improved both by administration of $\alpha$-adrenergic blocking agents to the donor prior to nephrectomy $[2$, 7] and by infusing the blocking agent directly into the renal artery during perfusion [7]. However, evidence that the intraarterial in- fusion of an $\alpha$-adrenergic blocking agent improves cortical flow as well as total renal perfusion flow has not been documented previously.

The present study shows that agonal anoxia will cause a decrease in perfusion flow to the cortex which persists throughout a $24-$ hr hypothermic pulsatile perfusion. However, intraarterial infusion of the adrenergic blocking agent, phentolamine, relieves the vasoconstriction and improves perfusion flow. Within $2 \mathrm{hr}$ of limited phentolamine infusion, the outer cortex received $75-80 \%$ of the perfusate flow, essentially equivalent to the control kidneys.

Kidneys subjected to agonal anoxia plus $40-50 \mathrm{~min}$ of warm ischemia also show decreased perfusion flow to the cortex, which does not resolve during $24 \mathrm{hr}$ of perfusion. However, in contrast to the group with anoxia alone, the vasoconstriction in this group does not dissipate with intraarterial phentolamine. This suggests the presence of additional changes that are not reversible catecholamine effects.

These data suggest that there are several conditions that might account for poor kidney flow characteristics during perfusion. Intrarenal vasoconstriction can be relieved with phentolamine administered directly in to the renal artery. Presumably, improved renal cortical flow during perfusion will result in better renal function after transplantation. However, this question has not yet been answered. If intrarenal vasoconstriction is not resolved, the decreased cortical flow may persist after transplantation and be aggravated by even minor degress of rejection [8]. This may be the kind of preserved kidneys that never function well after transplantation.

\section{SUMMARY}

Studies of the intrarenal distribution of perfusate during pulsatile hypothermic renal preservation have shown that donor agonal anoxia produces decreased perfusion flow to the cortex and an increase in medullary flow which is reversed by intraarterial infusion of phentolamine. Kidneys subjected to donor 
anoxia plus $40-50 \mathrm{~min}$ of warm ischemia also show similar cortical-medullary perfusion changes which are refractory to intraarterial phentolamine. The potential clinical consequences of changes in intrarenal perfusion and its treatment are discussed.

\section{REFERENCES}

1. Barkin, M., and Kerr, W. K. An aspect of the vascular role in the etiology of acute tubular necrosis. Surg. Gynecol. Obstet. 116:673, 1963.

2. Belzer, F., Reed, T., Pryor, J., Kountz, S., and Dunphy, J. Cause of renal injury in kidneys obtained from cadaver donors. Surg. Gynecol. Obstet. $130: 467,1970$.

3. Carriere, S., Thorburn, G. D., O'Morchoe, C. C., and Barger, A. C. Intrarenal distribution of blood flow in dogs during hemorrhagic hypotension. Circ. Res. 19:167, 1966.

4. Conn, H. L. Equilibrium distribution of radioxenon in tissue: Xenon-hemoglobin association curve. $J$. Appl. Physiol. 16:1065, 1961.

5. Dougherty, J., and Veith, F. J. Krypton 85 washout curves in isolated perfused kidneys. Arch. Surg. 105:464, 1972.

6. Miller, H. C., Alexander, J. W., Smith, E. J., and Fidler, J. P. Salutary effect of phentolamine on renal vasoconstriction in donor kidneys. Transplantation 17:201, 1974.

7. Miller, H. C., Alexander, J. W., and Nathan, P. Effect of warm ischemia damage on intrarenal distribution of flow in preserved kidneys. Surgery 72:193, 1972.

8. Rosen, S. M., Truniger, B. P., Kriek, H. R., Murray, J. E., and Merrill, J. P. Intrarenal distribution of blood flow in the transplanted dog kidney: Effect of denervation and rejection. J. Clin. Invest. 46:1239, 1967.

9. Small, A., Bell, R. T., Filo, R. S., and Woodward, C. R. Measurement of intracortical flow distribution in hypothermic isolated perfused kidneys. Amer. $J$. Physiol. 225:1 199, 1973.

10. Thorburn, G. D., Kopald, H. H., Herd, J. A., Hollenberg, M., O'Morchoc, C. C., and Barger, A. C. Intrarenal distribution of nutrient blood flow determined with krypton 85 in the unanesthesized dog. Circ. Res. 13:290, 1963. 